\title{
Impactos da prática de atividade física em estudantes com Doença Falciforme de Feira de Santana - Ba.
}

\author{
Gabriela Silva Santos $\mathbf{1}$; Ivanilde Guedes de Mattos ${ }^{2}$; \\ 1. Bolsista PIBIC/FAPESB, Graduanda em Educação Física, Universidade Estadual de Feira de Santana, e-mail: \\ gabrielasantosaa@gmail.com \\ 2. Orientadora, Departamento de saúde, Universidade Estadual de Feira de Santana, e-mail: \\ ivyfirmina@gmail.com
}

PALAVRAS-CHAVE: falciforme, saúde, educação física.

\section{INTRODUÇÃO}

A atividade física é conhecida por trazer diversos benefícios, corporais ou sociais, para os seus praticantes. Mesmo assim, quando falamos na prática de atividade física para pessoas com a Doença Falciforme, é causada uma polêmica, por acharem que para esse grupo em específico, a prática não é recomendada.

A Doença Falciforme (DF) é uma mutação genética que induz ao indivíduo produzir a hemoglobina $\mathrm{S}$ ao invés da hemoglobina A. Essa condição faz com que as hemácias dessas pessoas percam o formato natural de disco e tenha um formato de foice, originando o nome falciforme. A anemia falciforme, termo mais comum utilizado na sociedade, acontece quando o indivíduo recebe de herança genética dois genes $\mathrm{S}$, se tornando SS. Quando recebe apenas um, é chamado Traço Falciforme, ou AS. O termo "Doença Falciforme" compreende essas e outras hemoglobinopatias.

O que sabemos é que o cuidado com a pessoa com a DF deve existir, mas uma atividade bem planejada, respeitando os limites corporais dos participantes e com o objetivo de trazer benefícios e integrar socialmente só trará ganhos para a vida do paciente.

Diante disso, a nossa justificativa se dá na necessidade de conhecer e identificar os alunos e pacientes acometidos pela doença falciforme que praticam atividade física regularmente e investigar os seus efeitos na vida desses indivíduos. Tivemos como objetivos: Identificar jovens praticantes de atividade física com a DF em Feira de Santana - Ba e investigar quais os impactos sociais e corporais da prática de AF.

As perguntas norteadoras da nossa pesquisa foram: Quais os sujeitos que tem a doença falciforme e estão inseridos num contexto de práticas regulares de exercícios físicos tanto nas escolas quanto nos demais espaços em Feira de Santana - Bahia e quais os impactos corporais e sociais dessa prática?

\section{MATERIAL E MÉTODOS}

A pesquisa foi realizada no Centro de Referência Municipal à pessoa com Doença Falciforme, que fica na cidade de Feira de Santana - Ba e conta com diversos serviços para pessoas com a DF.

As crianças tinham entre seis e 18 anos, todas estudantes de escolas públicas de Feira de Santana. A maioria delas participa das sessões de fisioterapia oferecidas no próprio Centro de Referência e todas iam sempre acompanhadas dos seus pais e/ou responsáveis.

As visitas foram feitas de acordo ao horário das sessões da fisioterapia que são previamente marcadas e também de acordo ao horário de atendimento do pediatra que atendente. Os pais e/ou responsáveis eram abordados e a pesquisa era apresentada. Após o aceite dos pais, a pesquisa era explicada para as crianças e depois de todos 
concordarem, o Termo de Consentimento Livre e Esclarecido (TCLE) era assinado pelos pais e/ou responsáveis e por se tratar de menores de idade, o Termo de Assentimento Livre e Esclarecido (TALE) era assinado pela criança. Eram assinadas duas cópias de cada termo, sendo que uma fica com os participantes da pesquisa.

O método escolhido foi a entrevista semi - estruturada, onde existiam alguma perguntas pré estabelecidas, mas outras apareciam de acordo ao que era dito nas respostas anteriores.

Após esse processo, os resultados eram analisados de acordo ao discurso e discutidos à luz da literatura sobre o tema.

\section{RESULTADOS E/OU DISCUSSÃO (ou Análise e discussão dos resultados)}

Os perigos da prática de atividade física para pessoas com a DF são muito conhecidos e disseminados causando receio aos profissionais de Educação Física ao prescrever atividades para esse grupo e fazendo também com que médicos proíbam a prática para algumas pessoas. Um dos motivos dessa proibição, é que o aumento de temperatura corporal, comportamento natural do corpo durante o exercício, pode desencadear a Rabdomiólise, que pode ser definida como uma "lesão do músculo esquelético com liberação dos constituintes celulares para o plasma" (Uchoa e Fernandes, 2003, p.63) ou simplificando, uma necrose muscular. A rabdomiólise pode acontecer durante toda a vida do paciente com a DF, mas as chances de acontecer durante o exercício são maiores.

Os sintomas acontecem de maneira diferente para quem tem o Traço Falciforme e para as pessoas com a Anemia Falciforme. Para quem tem apenas o Traço, normalmente não tem nenhum sintoma ou efeito da doença, mas carrega a herança genética. Em um evento que aconteceu no Brasil em 2007 e que resultou em um artigo chamado "Consenso Brasileiro sobre atividades esportivas e militares e herança falciforme no Brasil" foram discutidas as condições para que pessoas com o Traço pudessem praticar atividades físicas e servir as Forças Armadas. Após uma grande discussão com especialistas, a conclusão foi que pessoas com o Traço podem praticar qualquer modalidade esportiva e podem servir as Forças Armadas sem que haja necessidade de nenhum teste de triagem para hemoglobinopatias. Apesar disso, Moreira et al(2002) traz que as pessoas com o Traço podem sim ter alguns sintomas se expostas ao estresse do exercício.

Podem ocorrer obstruções microvasculares, infarto da medula renal, hematúria, tendo maior incidência principalmente em pessoas de meia idade e idosos sedentários, enrijecimento das artérias, promovendo finalmente a polimerização de desoxihemoglobina $S$, induzindo assim a falcização e o infarto do baço, que são os mais característicos. (MOREIRA et al, 2002, p. 16)

Para as pessoas com a Anemia Falciforme, o processo acontece de outra maneira.

[...]exercício físico se praticado intensamente, produz mudanças fisiológicas que induzem a formação de polímeros, devido à Hemoglobina $\mathrm{S}(\mathrm{HbS})$ presente. Este sintoma causado pelo exercício ocorre devido desidratação, aumento da temperatura corpórea, hipoxia e acidose, que são evidentes em situações de estresse. Uma vez desencadeados, aumentam as chances de complicações para o portador de Anemia Falciforme. (KLUG apud MOREIRA et al,2002, p. 15)

As crianças pesquisadas foram selecionadas a partir de critérios préestabelecidos (1) Brincassem normalmente, sem grandes restrições, (2) Participassem 
das suas aulas de Educação Física escolar ou (3) se participassem das sessões de fisioterapia oferecida pelo Centro de Referência.

As crianças que relataram participar de brincadeiras sem restrições informaram não sentir dores, mas às vezes se sentiam cansadas. Uma das crianças tinha passado por transfusão de sangue recentemente, excluindo os quadros de dor totalmente. Todas elas não relataram em nenhum momento que a DF fosse empecilho para as suas brincadeiras, o que corrobora o achado de Santos e Mattos (2017)

A criança, por outro lado, não encontra dificuldades em modificar as brincadeiras para se encaixar à sua realidade. Apesar de todos os cuidados que devem ser tomados e toda a limitação que a doença traz, observando-as em campo pudemos perceber que entre elas não há essa separação estereotipada na qual esperamos. (SANTOS e MATTOS, 2017, p. 3)

Já nas aulas de Educação Física escolar, as crianças que participavam das aulas regularmente afirmaram que seus professores sabiam da sua condição e eles participavam das aulas sem que fosse feita nenhuma alteração em relação a atividade dos seus colegas ou em relação a intensidade da atividade. Apesar disso, quando perguntados em relação a se sentir cansados durante a atividade, um deles relatou que se fosse preciso sair no meio da atividade o seu professor permitia prontamente.

Nenhuma das crianças pesquisadas participava de outro programa de atividade física. Mesmo com os cuidados, a prática de atividade física deve ser indicada a esses sujeitos encorajados. No entanto, a campo é possível identificar que muitas vezes esses indivíduos não são encorajados a participar de atividades que possuem como característica um maior dispêndio metabólico, como esportes e dança pela superproteção dos pais, como corrobora Segava et al (2009)

Esta proteção exacerbada dos pais, somado a cautela dos médicos é muito comum visto que não existem estudos que verifiquem o comportamento destas crianças em programas de atividade física regular a médio e longo prazo. (SEGAVA et al, 2009,p. 246)

Já no Centro de Referência durante a pesquisa os pais que ficavam ao lado enquanto as crianças respondiam as nossas perguntas falavam que apenas confiaria em deixar seus filhos praticarem alguma modalidade esportiva, por exemplo, se conhecessem muito bem os profissionais responsáveis, ou se o local fosse próximo a sua casa. Mesmo assim, mostravam inteira confiança nas sessões de fisioterapia em que seus filhos estavam e relataram benefícios.

A fisioterapia é uma grande aliada das pessoas com a DF. As crianças que participavam das sessões regularmente relataram muitas mudanças em relação ao período a qual não participavam. Essas mudanças aconteceram principalmente em relação às dores nos ossos e articulações. Uma deles disse: "Nunca fui de sentir muitas dores, mas sempre que meus ossos começam a doer, venho para a fisioterapia e passa na hora".

Outro benefício bastante citado foi em relação ao cansaço. Uma das crianças é asmática, além da DF e sempre teve muito cansaço e algumas internações por conta da associação das doenças. Foi informado que após a fisioterapia ele nunca mais tinha relatado nenhuma complicação respiratória. Algumas crianças relataram a melhora na respiração e até no sono.

As sessões de fisioterapia são individuais e planejadas de acordo com cada caso. O Centro de Referência possui duas profissionais responsáveis e as crianças participam 
de uma a duas vezes na semana. As sessões trabalham articulações através de atividades de alongamentos e exercícios que trabalham o trato respiratório.

Foi constatada também uma melhora no encurtamento do íliopsoas, característica comum em pessoas com a DF.

Ainda que não de forma sistematizada e planejada com que a atividade física apareça na vida dessas crianças é observável que elas apresentam uma diferença na qualidade de vida em relação àqueles que não praticam nenhuma. Um fator que demarca essa diferença se dá sobre a hospitalização que não foi citada como algo comum em nenhum dos casos pesquisados.

\section{CONSIDERAÇÕES FINAIS}

Prescrever atividades físicas para pessoas com a DF não nega um dos primeiros princípio do treinamento desportivo, que é o princípio da individualidade biológica. Assim como para qualquer outro indivíduo, falcêmico ou não, a atividade física precisa de uma regularidade e precisa ser prescrita de maneira individualizada, respeitando os limites impostos pela doença. Além disso, não podemos perder de vista, a atividade física traz uma maior interação social, como foi observado em campo, além de todos os benefícios corporais já citados.

Mesmo que pareça um grande desafio ser responsável por uma atividade física para pessoas com DF, é de extrema importância que os profissionais de Educação Física estejam atentos e atualizados acerca do tema para garantir esses benefícios e contribuir com uma maior qualidade de vida para essas pessoas.

\section{REFERÊNCIAS}

MOREIRA, Gisele Fabris et al. Aspectos fisiológicos da atividade física em portadores de anemia falciforme. 2002. 31 f. Monografia (Especialização) - Curso de Fisiologia do Exercício, Universidade Federal de São Paulo, São Paulo, 2002.

SANTOS, Gabriela Silva; Mattos, Ivanilde Guedes de. Lazer e sociabilidade dos alunos com doença falciforme. In: Anais Semana de Iniciação Científica, 2017. Universidade Estadual de Feira de Santana, 2017.

SEGAVA, Nayara Bernardes et al. Caracterização do uso de atividades físicas em crianças e adolescentes com anemia falciforme. Revista de Terapia Ocupacional da Universidade de São Paulo, São Paulo, v. 24, n. 3, p.242-249, set. 2009.

UCHOA, Ricardo Barreira; FERNANDES, Cláudia Regina. Rabdomiólise Induzida por exercício e Risco de Hipertermia Maligna. Relato de caso. Revista Brasileira de Anestesiologia, Fortaleza, v. 53, n. 1, p.63-68, fev. 2003. 